\title{
Execution Increment of Classifiers using Combination of Clustering and Examination Techniques
}

\author{
P.Nandhini, R. Velvizhi, A.V. Allin Geo, Nikita sharma
}

\begin{abstract}
Therapeutic masters require a solid guess thinking to separate Diabetes. Information mining is the way toward isolating information from trade viewpoints and spreading out it into noteworthy data. The basic objective of information mining is to find new cases for the clients and to make an understanding of the information cases to give basic and huge data to the clients. Information mining is related with find vital cases to help in the basic errands of therapeutic affirmation and treatment. In this paper, execution examination of direct assembling figurings and joined packaging and course of action calculations are done. It was discovered that the joined packaging depiction procedure was superior to the essential social occasion approach.
\end{abstract}

\section{INTRODUCTION}

Data mining is the methodology of adjusted demand of cases in context of information designs acquired from a dataset. Diverse estimations have been made and acknowledged to clear data and find learning traces. Information Mining, besides prominently known as Knowledge [7],[9] ,[11]

Disclosure in Databases (KDD). The KDD technique is related on gigantic extent of information from set away database/information flow center/any information record for emptying designs, affiliations, changes, characteristics and covered or center data utilizing tallies and structures. [14],[ 16], [18] Social event is a crucial undertaking in the information examination that requires the enhancement of a classifier, that is, a limit that relegates a class stamp to outlines depicted by a strategy of properties. It is one of the basic businesses of information mining. This procedure predicts firm class marks. It is a controlled learning framework. Demand of information is especially conventional undertaking in information mining. The objective of plan is to accurately envision the respect. Social occasion Algorithms utilized are NavieBayes, BayesNet,

Revised Manuscript Received on July 22, 2019

P.Nandhini, Department of CSE, Bharath Institute of Higher Education and Research, Chennai, Tamilnadu, India.

R. Velvizhi Department of CSE, Bharath Institute of Higher Education and Research, Chennai, Tamilnadu, India

A.V. Allin Geo Department of CSE, Bharath Institute of Higher Education and Research, Chennai, Tamilnadu, India.

Nikita sharma, , Student,Department of CSE, Bharath Institute of Higher Education and Research, Chennai, Tamilnadu, India
OneR and J48.

\section{PROPOSED METHOD}

Demand is the technique which finds the fundamental properties among an arrangement of articles in a database and portrays them into various classes, as exhibited by a social affair demonstrate. Packaging is the undertaking of separating an alternate get-together into various close subgroups or social events. In this proposed system first the social affair estimation is related on the dataset with the assistance of any pressing figurings, for example, Simple K-Means and Density Based Clustering. Social event figuring fuses the quality "package on the dataset. Beginning now and into the not so distant, orchestrate check is related on this grouped dataset. This methodology gives happens with a dominating precision than the immediate social event approach.

\section{A. Dataset}

Delicate utilizations edifying rundown (Attribute-relationship) record of ".arff" plot. This illuminating record incorporates trademark names, sorts, values and the information. In this paper, "Diabetes Diagnosis" is utilized. Illuminating rundown contains eight properties, one class property and 768 cases.

\section{B. Gathering}

Bunching is an unsupervised framework for information mining. In social event client needs to depict their own specific classes as appeared by class factors, here no predefined classes are available. In weka number of bunching calculations are open like bug getting system, DBSCAN, Farthest First, SimpleK-Means and so on.

Coordinate K-Means tally:

The principal advancement of $\mathrm{k}$-recommends gathering is fundamental. Regardless, we pick number of social occasion $\mathrm{K}$ and we anticipate the centroid or purpose of intermingling of these groups. We can acknowledge any abstract difficulties as the shrouded centroids or the rule $\mathrm{K}$ things can also fill in as the fundamental centroids. By then the $\mathrm{K}$ derives figuring will do the four stages underneath until solidifying. [19],[21],[23] 


\section{Thickness Based Clustering}

Thickness based packaging estimations try to discover bundles in light of thickness of server farms in a region. The key thought of thickness based assembling is that for every occasion of a package the region of a given range (Eps) needs to contain atleast a base number of cases (MinPts). To discover a social occasion, it begins with a self-earnest occasion (p) in informative record (D) and recovers all instances of D concerning Eps and Min Pts. The calculation impacts use of a spatial information to structure to find focuses inside Eps seclude from the center purposes behind the social occasions. Estimation is given underneath. [20], [22], [24]

1) Start with an enthusiastic beginning stage that has not been cruised by.

2) Extract the zone of this point utilizing $\varepsilon$ (All focuses which are inside the $\varepsilon$ disengage are neighborhood).

3 ) If there is agreeable neighborhood around this point by then assembling procedure begins and point is discrete as went to else this point is separate as disturbance (Later this point can change into the bit of the bunch).

4) If a point supposedly is a touch of the social event then its $\varepsilon$ neighborhood is in like way the bit of the pack and the above system from mastermind 2 is repeated for all $\varepsilon$ neighborhood focuses. This is repeated until the point that all fixations in the pack are settled.

5) A new unvisited point is recovered and dealt with, actuating the divulgence of a further assembling or hullabaloo.

6) This process proceeds until the point that all focuses are independent as went to. [38],[40],[42]

\section{GROUPING}

Information mastermind is an essential undertaking in information mining. For asking for an information mining issue, measures of depiction calculations are utilized like Bayes, Functions, misc, Rules, Trees and so forth. The reason for depiction is to figure the estimations of each factor and dole out those parts to encouraged predefined classes. In this paper, four different social affair calculations have been utilized, which have been recorded underneath:

Naïve Bayes (NB): A free section likelihood outline, it depends upon the Bayes theory and is in this manner a probabilistic classifier.

BayesNet(BN) : By utilizing the bayes hypothesis BayesNet can be made. To structure a Baysian orchestrate first restrictive likelihood of each middle point must be figured. Non-cyclic diagrams are utilized to address the structure.

OneR : OneR, another way to deal with state "One Rule", is an immediate, correct, gathering estimation that influences one to supervise for every pointer in the information, by then picks the continue running with the humblest all out mess up as its "one run the show". J48: It is

a refreshed sort of C4.5 estimation. Precisely when a particular information thing is asked for, it will be segregated in various dimensions beginning from root focus point to the leaf or terminal focus ceaselessly.

\section{TEST RESULTS}

The examinations performed on the dataset gave the outcomes as appeared as takes after. This table demonstrates the accuracy extent of the immediate social occasion calculations, coordination of collection and depiction utilizing Simple K-Means and mix of packaging and game-plan utilizing Density Based Clustering Algorithm. From the table, obviously the execution of classifiers has been enhanced coming about to bunching.

\section{CONCLUSION}

In this paper four undeniable classifiers are made with the central k-derives gathering figuring and thickness based packaging estimation. This coordination system was related on "Diabetes" instructive record. From the acumen and examination it was thought about that the execution of Density Based + NavieBayes is superior to different calculations due to the running with highlights: [26],[28],[30]

1. Number of feasibly depicted occasions is more

2. Absolute stumbles are less.

There are enormous measures of classifiers present and different other information mining devices are open. So the future work will be built up on different classifiers that can be related on the enlightening rundown what's more to apply other information mining devices on the instructive rundown with the genuine target that and furthermore can be ordinary be perceived. Above calculations can be related with different datasets so as to watch whether a similar figuring gives the most lifted precision.

Pressing is an information mining system to add up to the close information into a social occasion and disparate information into various gatherings. Packaging is an unsupervised learning system; it administers finding a structure in a get-together of unlabeled information. Gathering is the course toward coordinating articles into packs whose individuals are essentially indistinguishable here and there or another. A get-together is along these lines a social event of articles which are equal among them and are not at all like the things having a place with different packs. Get-together Algorithms utilized are Simple K-Means and Density Based Clustering[37],[39],[41]

Trade off of accumulation and demand strategy is valuable notwithstanding when the dataset contains missing respects. Execution of classifiers has been enhanced record of sorting out. 


\section{REFERENCES}

[1] Kumaravel A., Rangarajan K.,Algorithm for automaton specification for exploring dynamic labyrinths,Indian Journal of Science and Technology,V-6,I-SUPPL5,PP-4554-4559,Y-2013

[2] P. Kavitha, S. Prabakaran "A Novel Hybrid Segmentation Method with Particle Swarm Optimization and Fuzzy C-Mean Based On Partitioning the Image for Detecting Lung Cancer" International Journal of Engineering and Advanced Technology (IJEAT) ISSN: 2249-8958, Volume-8 Issue-5, June 2019

[3] Kumaravel A., Meetei O.N.,An application of non-uniform cellular automata for efficient cryptography,2013 IEEE Conference on Information and Communication Technologies, ICT 2013,V-,I-,PP-1200-1205,Y-2013

[4] Kumarave A., Rangarajan K.,Routing alogrithm over semi-regular tessellations,2013 IEEE Conference on Information and Communication Technologies, ICT 2013,V-,I-,PP-1180-1184,Y-2013

[5] P. Kavitha, S. Prabakaran "Designing a Feature Vector for Statistical Texture Analysis of Brain Tumor" International Journal of Engineering and Advanced Technology (IJEAT) ISSN: 2249-8958, Volume-8 Issue-5, June 2019

[6] Dutta P., Kumaravel A.,A novel approach to trust based identification of leaders in social networks,Indian Journal of Science and Technology,V-9,I-10,PP--,Y-2016

[7] Kumaravel A., Dutta P.,Application of Pca for context selection for collaborative filtering,Middle - East Journal of Scientific Research,V-20,I-1,PP-88-93,Y-2014

[8] Kumaravel A., Rangarajan K.,Constructing an automaton for exploring dynamic labyrinths,2012 International Conference on Radar, Communication and Computing, ICRCC 2012,V-,I-,PP-161-165,Y-2012

[9] P. Kavitha, S. Prabakaran "Adaptive Bilateral Filter for Multi-Resolution in Brain Tumor Recognition" International Journal of Innovative Technology and Exploring Engineering (IJTEE) ISSN: 2278-3075, Volume-8 Issue-8 June, 2019

[10] Kumaravel A.,Comparison of two multi-classification approaches for detecting network attacks, World Applied Sciences Journal,V-27,I-11,PP-1461-1465,Y-2013

[11] Tariq J., Kumaravel A.,Construction of cellular automata over hexagonal and triangular tessellations for path planning of multi-robots,2016 IEEE International Conference on Computational Intelligence and Computing Research, ICCIC 2016,V-,I-,PP--,Y-2017

[12] Sudha M., Kumaravel A.,Analysis and measurement of wave guides using poisson method,Indonesian Journal of Electrical Engineering and Computer Science,V-8,I-2,PP-546-548,Y-2017

[13] Ayyappan G., Nalini C., Kumaravel A.,Various approaches of knowledge transfer in academic social network,International Journal of Engineering and Technology,V-,I-,PP-2791-2794,Y-2017

[14] Kaliyamurthie, K.P., Sivaraman, K., Ramesh, S. Imposing patient data privacy in wireless medical sensor networks through homomorphic cryptosystems 2016, Journal of Chemical and Pharmaceutical Sciences 92.

[15] Kaliyamurthie, K.P., Balasubramanian, P.C. An approach to multi secure to historical malformed documents using integer ripple transfiguration 2016 Journal of Chemical and Pharmaceutical Sciences 92 .

[16] A.Sangeetha,C.Nalini,"Semantic Ranking based on keywords extractions in the web", International Journal of Engineering \& Technology, 7 (2.6) (2018) 290-292

[17] S.V.GayathiriDevi,C.Nalini,N.Kumar,"An efficient software verification using multi-layered software verification tool "International Journal of Engineering \& Technology, 7(2.21)2018 454-457

[18] C.Nalini,ShwtambariKharabe,"A Comparative Study On Different Techniques Used For Finger - Vein Authentication", International Journal Of Pure And Applied Mathematics, Volume 116 No. 8 2017, 327-333, Issn: 1314-3395

[19] M.S. Vivekanandan and Dr. C. Rajabhushanam, "Enabling Privacy Protection and Content Assurance in Geo-Social Networks", International Journal of Innovative Research in Management, Engineering and Technology, Vol 3, Issue 4, pp. 49-55, April 2018

[20] Dr. C. Rajabhushanam, V. Karthik, and G. Vivek, "Elasticity in Cloud Computing", International Journal of Innovative Research in Management, Engineering and Technology, Vol 3, Issue 4, pp. 104-111, April 2018.
[21] K. Rangaswamy and Dr. C. Rajabhushanamc, "CCN-Based Congestion Control Mechanism In Dynamic Networks", International Journal of Innovative Research in Management, Engineering and Technology, Vol 3, Issue 4, pp. 117-119, April 2018.

[22] Kavitha, R., Nedunchelian, R., "Domain-specific Search engine optimization using healthcare ontology and a neural network backpropagation approach", 2017, Research Journal of Biotechnology, Special Issue 2:157-166

[23] Kavitha, G., Kavitha, R., "An analysis to improve throughput of high-power hubs in mobile ad hoc network" , 2016, Journal of Chemical and Pharmaceutical Sciences, Vol-9, Issue-2: 361-363

[24] Kavitha, G., Kavitha, R., "Dipping interference to supplement throughput in MANET" , 2016, Journal of Chemical and Pharmaceutical Sciences, Vol-9, Issue-2: 357-360

[25] Michael, G., Chandrasekar, A.,"Leader election based malicious detection and response system in MANET using mechanism design approach", Journal of Chemical and Pharmaceutical Sciences(JCPS) Volume 9 Issue 2, April - June 2016.

[26] Michael, G., Chandrasekar, A.,"Modeling of detection of camouflaging worm using epidemic dynamic model and power spectral density", Journal of Chemical and Pharmaceutical Sciences(JCPS) Volume 9 Issue 2, April - June 2016.

[27] Pothumani, S., Sriram, M., Sridhar, J., Arul Selvan, G., Secure mobile agents communication on intranet,Journal of Chemical and Pharmaceutical Sciences, volume 9, Issue 3, Pg No S32-S35, 2016

[28] Pothumani, S., Sriram, M., Sridhar, Various schemes for database encryption-a survey, Journal of Chemical and Pharmaceutical Sciences, volume 9, Issue 3, Pg NoS103-S106, 2016

[29] Pothumani, S., Sriram, M., Sridhar, A novel economic framework for cloud and grid computing, Journal of Chemical and Pharmaceutical Sciences, volume 9, Issue 3, Pg No S29-S31, 2016

[30] Priya, N., Sridhar, J., Sriram, M. "Ecommerce Transaction Security Challenges and Prevention Methods- New Approach" 2016 ,Journal of Chemical and Pharmaceutical Sciences, JCPS Volume 9 Issue 3.page no:S66-S68

[31] Priya, N.,Sridhar,J.,Sriram, M."Vehicular cloud computing security issues and solutions" Journal of Chemical and Pharmaceutical Sciences(JCPS) Volume 9 Issue 2, April - June 2016

[32] Priya, N., Sridhar, J., Sriram, M. "Mobile large data storage security in cloud computing environment-a new approach" JCPS Volume 9 Issue 2. April - June 2016

[33] Anuradha.C, Khanna.V, "Improving network performance and security in WSN using decentralized hypothesis testing "Journal of Chemical and Pharmaceutical Sciences(JCPS) Volume 9 Issue 2, April - June 2016 .

[34] Anuradha.C, Khanna.V, "A novel gsm based control for e-devices" Journal of Chemical and Pharmaceutical Sciences(JCPS) Volume 9 Issue 2, April - June 2016

[35] Anuradha.C, Khanna.V, "Secured privacy preserving sharing and data integration in mobile web environments " Journal of Chemical and Pharmaceutical Sciences(JCPS) Volume 9 Issue 2, April - June 2016.

[36] Sundarraj, B., Kaliyamurthie, K.P. Social network analysis for decisive the ultimate classification from the ensemble to boost accuracy rates 2016 International Journal of Pharmacy and Technology 8

[37] Sundarraj, B., Kaliyamurthie, K.P. A content-based spam filtering approach victimisation artificial neural networks 2016 International Journal of Pharmacy and Technology 83.

[38] Sundarraj, B., Kaliyamurthie, K.P. Remote sensing imaging for satellite image segmentation 2016 International Journal of Pharmacy and Technology $8 \quad 3$.

[39] Sivaraman, K., Senthil, M. Intuitive driver proxy control using artificial intelligence 2016 International Journal of Pharmacy and Technology $8 \quad 4$.

[40] Sivaraman, K., Kaliyamurthie, K.P. Cloud computing in mobile technology 2016 Journal of Chemical and Pharmaceutical Sciences 92.

[41] Sivaraman, K., Khanna, V. Implementation of an extension for browser to detect vulnerable elements on web pages and avoid click jacking 2016 Journal of Chemical and Pharmaceutical Sciences 92. 


\section{AUTHORS PROFILE}

P.Nandhini, Assistant Professor, Department of Computer Science \& Engineering, Bharath Institute of Higher Education and Research, Chennai, India

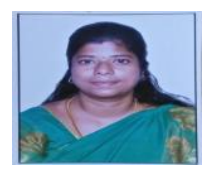

R.Velvizhi, Assistant Professor, Department of Computer Science \& Engineering, Bharath Institute of Higher Education and Research, Chennai, India

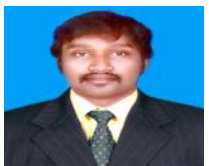

Allin Geo, Assistant Professor, Department of Computer Science \& Engineering, Bharath Institute of Higher Education and Research, Chennai, India

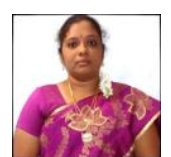

Nikita Sharma, Student, Department of Computer Science \& Engineering, Bharath Institute of Higher Education and Research, Chennai, India 